\title{
Healthy obese child: when and in whom do comorbidities develop?
}

\author{
Ewa Małecka-Tendera \\ Department of Paediatrics, Paediatric Endocrinology and Diabetes, Medical University of Silesia, Katowice, Poland
}

\begin{abstract}
Obesity is associated with an increased risk of premature death as individuals with obesity typically develop type 2 diabetes (T2D), dyslipidemia, fatty liver disease, hypertension and cardiovascular disease (CVD). However a subgroup of obese patients seem to be protected against metabolic complications. The aim of the review is to summarize current knowledge on the so-called "healthy obesity" with a focus on the paediatric population. There are several data showing that certain obese adolescents do not experience metabolic complications. On the other hand, other clinical longitudinal studies suggest that metabolically healthy obesity (MHO) is a dynamic concept that should be taken into account over time. However, there is an agreement that some obese adolescents should be monitored more closely for adverse events, while others may not be at a high risk. Therefore, whether MHO in youngsters is a questionable entity remains a matter of debate.
\end{abstract}

Key words: obesity, child, comorbidity.

Health is a level of functional or metabolic efficiency of a living being [1]. In humans, it is the general condition of a person's mind, body and spirit, usually meaning to be free from illness, injury or pain. The World Health Organization (WHO) defined health in its broader sense in 1946 as "a state of complete physical, mental, and social wellbeing and not merely the absence of disease or infirmity".

Obesity is generally regarded as a health hazard in adults, mostly due to a well-documented risk factor for type 2 diabetes (T2D) and coronary heart disease [2,3]. However, there is a substantial body of evidence that a subgroup of obese and overweight persons do not experience increased cardiovascular disease (CVD) risk factors and their mortality risk is comparable to that of normal weight subjects. The prevalence of the so-called "metabolically healthy obesity" (MHO) in adults in different studies ranges from $10 \%$ to $30 \%$ [4-7].

According to the WHO, obesity is considered a disease itself [1]. In the light of this statement it is rather strange to divide obesity into healthy and unhealthy. Nevertheless, we all know that a certain number of obese persons are free from some (most frequently investigated) obesity-related metabolic consequences. The questions that remain to be answered are whether we have enough scientific proof to use the term "healthy obesity" and whether we can distinguish metabolically healthy and unhealthy obese individuals by using different obesity indices. Prevalence of $\mathrm{MHO}$ varies considerably according to the definition used. Its prevalence significantly decreases with age, thus it can be as well a temporary phenomenon $[6,8]$.

As the prevalence of overweight and obesity in the paediatric population has increased dramatically for the last 2 decades, some forecast suggested that the obesity epidemic would reverse the trend of the declining rate of death from CVD leading to a shorter life span for today's young generation [9].

Despite well-known complications of childhood obesity, several studies have recently showed that body mass index (BMI) in early childhood does not appear to be related to the increased CVD risk in later life. In the Aberdeen Children study, no association was found between BMI at the age of 5 years and coronary heart disease in later life [10]. In 2006, Lawlor et al. investigated the association between early life BMI and risk of ischaemia and stroke in 3 large cohorts in whom BMI was estimated between 1922 and 1950. The results of their study did not provide strong evidence that being overweight or obese in childhood is associated with the future cardiovascular risk [11]. 
Childhood and adolescent obesity were believed to increase the CVD risk independently of adult BMI. However, the analysis of data coming from four prospective cohort studies that measured childhood and adult BMI showed that children who become non obese adults had the same risk of type 2 diabetes, hypertension, dyslipidemia and carotid artery sclerosis as those who were never obese [12]. Metabolic disorders present in many obese children therefore seem to be reversible and childhood obesity does not permanently increase the CVD risk.

There are convincing data that the absence of metabolic disorders in phenotypically obese people is probably due to preserved insulin sensitivity [13-16]. At a given BMI there are obese (healthy) individuals being either extremely insulin sensitive or extremely insulin resistant. There is no cutoff clearly separating distinct insulin-sensitive and insulin-resistant subgroups. The healthy obese phenotype is characterized by preserved insulin sensitivity, relatively low visceral fat mass and normal adipose tissue function. However, initially MHO individuals undergo adverse metabolic changes associated with obesity over time, therefore metabolically healthy obesity may not be a stable condition $[11,17,18]$. While there were significant lower levels of low-density lipoprotein and triglycerides in $\mathrm{MHO}$ among patients younger than 40 years, the significance was lost among older patients. Metabolically healthy but obese participants also had a better fitness than metabolically abnormal obese participants. Despite having a lower muscle mass, these individuals appear to have higher muscle strength, suggesting higher muscle quality that potentially may explain the favourable metabolic profile [15].

Recent studies suggest that inflammation of visceral adipose tissue, epicardial fat, ectopic fat deposition and adipose tissue dysfunction mediate insulin resistance in human obesity independently of total body fat mass $[19,20]$. This suggests that mechanisms beyond a positive caloric balance, such as inflammation and adipokine release, determine the pathological metabolic consequences in patients with obesity.

In fact obese preschool and prepubertal children do not frequently experience metabolic complications and their insulin sensitivity is usually well preserved [2123 ]. They are also naturally active and physical activity is known to exert a beneficial effect on visceral fat content. Due to the shorter period of fat accumulation, their adipose tissue dysfunction, responsible for the increased level of inflammatory markers, is also less pronounced. Therefore, is there an age limit when obesity-related complications start?

In obese adolescents several complications of the excess body weight such as dyslipidemia, hypertension and impaired glucose tolerance have been described [2, 23-26]. The increasing rate of childhood obesity in de- veloped and developing countries results in an increased prevalence of metabolic syndrome and T2D. The results of the National Survey of Children's Health from 2007 showed a strong association of obesity and T2D, however obesity predicted diabetes only for children of 15 years or older [26]. A high percentage of younger children with impaired glucose tolerance converted to normal glucose tolerance in the prospective studies [27,28].

Obesity is the main component of metabolic syndrome (MS). In the UK population, one third of obese children and adolescents were found to have MS according to WHO criteria. Still two thirds of them did not have all components of MS, including 15\% of those with a particularly high waist-to-height ratio [2]. Results of the Bogalusa Heart Study have shown that MHO children were more likely to retain their status in adulthood. Despite markedly increased MBI these children (and adults) showed a cardiometabolic profile generally comparable to that of normal weight children [22].

Visceral fat was found to be independently and negatively associated with insulin sensitivity and positively related to insulin secretion in obese Hispanic and Caucasian children $[12,13,29]$. This relationship was independent of overall adiposity and subcutaneous abdominal fat. These findings support the hypothesis that visceral fat accumulation increases the risk of T2D. Stronger obesityhealth associations were also found for white than for Hispanic children, which points out to racial and ethnic differences [13].

WHO description of health also concerns "a state of social well-being" [1]. Several studies showed that obesity has a clear negative impact on self-esteem. However, young school children may not perceive their weight as excessive. They are also commonly not regarded as obese by the family members as most parents of overweight and obese preschoolers classify their off-springs as normal weight [30-33]. The UK studies show a high level of body weight underestimation in 7-9-year-old children, particularly in overweight girls, which contradicts a general assumption that most girls believe they are overweight or fat regardless of their real body size [32]. The change toward underestimation could be due to changes in societal norms and the shift towards higher body weight being regarded as "normal". Overweight and obese teenagers may experience more severe stigmatization, particularly by their peers $[33,34]$. However in the societies where up to $40 \%$ of school children are obese or overweight this problem may be anecdotal. In fact in one of the studies coming from the UK, obesity was associated with higher self-esteem among black African girls and not associated with low self-esteem among white British girls. In a study conducted in the US obesity in boys had no impact on self-esteem in black, Hispanic and white boys. An association between obesity and self-perception in obese ad- 
olescents is specific and it cannot be generalized that all obese children have low self-esteem [35].

\section{Conclusions}

Many obese children and adolescents will progress into adult life following the same BMI trajectory. Majority of them will develop metabolic and CV complications. However up to $30 \%$ of individuals seem to be protected against obesity-related diseases and they may not significantly improve their metabolic parameters by the weight loss or life style changes [36]. Prevention and treatment of childhood obesity is an enormous task with so far quite low success rate. It would be important to identify those children who are at the highest risk of developing early complications and who will benefit the most from even moderate weight loss.

\section{Disclosure}

Author reports no conflict of interest.

\section{References}

1. World Health Organization. Constitution of the WHO. New York 2010; http//apps.who.

2. Saydah S, McKeever-Bulland K, Imperator G, Geiss L, Gregg EW. Cardiometabolic risk factors among UD adolescents and young adults and risk of early mortality. Pediatrics 2013; 131: e679-686.

3. Adams KF, Leitzmann MF, Ballard-Barbash R et al. Body mass and weight change in adults in relation to mortality risk. Am J Epidemiol 2014; 179: 135-144.

4. Blucher M. The distinction of metabolically "healthy" from "unhealthy" obese individuals. Current Opin Lipidol 2010; 21: 38-43.

5. Despres J-P. What is "metabolically healthy obesity?". From epidemiology to pathophysiological insights. J Clin Endocrinol Metabol 2012; 97: 2283-2285.

6. Hamer M, Stamatakis E. Metabolically healthy obesity and risk of all-cause and cardiovascular mortality. J Clin Endocrinol Metabol 2012; 97: 2482.

7. Hinnouho M, Czernichow S, Dugravot A, Batty GD, Kivimaki M, Singh-Manoux A. Metabolically healthy obesity and risk of mortality. Diabetes Care 2013; 36: 2294-2300.

8. Stefan N, Haring HU, Schulze M. Metabolically healthy obesity: epidemiology, mechanisms and clinical implications. Lancet Diabetes Endocrinol 2013; 1: 152-162.

9. Olshansky SJ, Passaro DJ, Hershow RC, et al. A potential decline in life expectancy in the US in the 21 century. N Engl J Med 2005; 352: 1138-1145.

10. Lawlor DA, Leon DA. Association of body mass index and obesity measured in early childhood with risk of coronary heart disease and stroke in middle age. Findings from the Aberdeen Children of 1950s Perspective Cohort Study. Circulation 2005; 111: 1891-1896

11. Lawlor DA, Martin RM, Gunnell D, et al. Association of body mass index measured in childhood, adolescence and young adulthood with ischemic heart disease and stroke: findings from 3 historical cohort studies. Am J Clin Nutr 2006; 83: 767-773.

12. Juonala M, Magnussen CG, Berenson GS, Venn A, et al. Childhood adiposity, adult adiposity, and cardiovascular risk factors. N Engl J Med 2011; 365: 1876-1885.
13. Cruz M, Bergman RN, Goran MI. Unique effect of visceral fat on insulin sensitivity in obese Hispanic children with a family history of type 2 diabetes. Diabetes Care 2002; 25: 1631-1636.

14. Aung K, Lorenzo C, Hinojosa MA, Haffner SM. Risk of developing diabetes and cardiovascular disease in metabolically unhealthy normal-weight and metabolically healthy obese individuals. J Clin Endocrinol Metab 2014; 99: 462-468.

15. Denis GV, Hamilton JA. Healthy obese persons: How can they be identified and do metabolic syndrome profiles stratify risk? Curr Opin Endocrinol Diabetes Obes 2013; 20: 369-376.

16. Guerrero-Romero F, Aradillas-Garcia C, Simental-Mendia LE, et al. Biochemical characteristics and risk factors for insulin resistance at different levels of obesity. Pediatrics 2013; 131: e1211-1217.

17. Vukovic R, Mitrovic K, Soldatovic I, et al. Insulin-sensitive obese children display a favourable metabolic profile. Eur J Pediatr 2013; 171: 201-206.

18. Soriguer F, Gutierrez-Repiso C, Rubio-Martin E, et al. Metabolically healthy but obese, a matter of time. Findings from the prospective Pizarra study. J Clin Endocrinol Metab 2013; 98: 2318-2325.

19. Mazur A, Ostański M, Telega G, Małecka-Tendera E. Is epicardial fat tissue a marker of metabolic syndrome in obese children? Atherosclerosis 2010; 211: 596-600.

20. Pataky Z, Bobbioni-Harsch E, Golay A. Open questions about metabolically normal obesity. Int J Obes 2010; 34: S18-23.

21. Mazur A, Grzywa M, Małecka-Tendera E, Telega G. Prevalence of glucose intolerance in school age children. Population based cross-sectional study. Acta Paediatr 2007; 96: 1799-1802.

22. Shengxu L, Chen W, Srinivasan SR, Xu J, Berenson GS. Relation of childhood obesity/cardiometabolic phenotypes to adult cardiometabolic profile. Am J Epidemiol 2012; 176: S142-149.

23. Seery T, Moodie D, Cephus C, Sexson K. Lipid profiles performed at the time of routine physical examinations in 9-11-year-olds within Texas children's pediatric associates primary care pediatric clinics. American College of Cardiology 2014 Scientific Sessions; March 31, 2014; Washington, DC. Abstract 1259-149.

24. Bokor S, Frelut ML, Vania A, et al. Prevalence of metabolic syndrome in European children. Int J Pediatr Obes 2008; 3 (Suppl 2): 3-8.

25. Schubert CM, Sun SS, Burns TI, et al. Predictive ability of childhood metabolic components for adult metabolic syndrome and type 2 diabetes. J Pediatr 2009; 155: e7-11.

26. Thomsen M, Nordesgaard B. Myocardial infarction and ischemic heart disease in overweight and obesity with and without metabolic syndrome. JAMA Intern Med 2014; 174: 15-22.

27. Kleber M, Lass N, Papcke S, Wabitsch M, Reinehr R. One year follow-up of untreated obese white children and adolescents with impaired glucose tolerance: high conversion rate to normal glucose tolerance. Diabetic Med 2010; 27: 516.

28. Małecka-Tendera E, Koehler B, Wiciak B, Ramos A. Impaired glucose tolerance in obese children - a long-term prospective study. In: Ditschuneit H, Gries FA, Hauner H, Schusdziarra V, Wechsler JG (eds.). Obesity in Europe 1993. Libbey \& Co 1994, pp. 153-158.

29. Zachurzok-Buczyńska A, Klimek K, Firek-Pędras M, Małecka-Tendera E. Are metabolic syndrome and its components in obese children influenced by overweight status or the insulin resistance? Pol J Endocrinol 2011; 62: 102-108.

30. Saxon J, Hill C, Chadwich P, Wardle J. Weight status and perceived body size in children. Arch Dis Child 2009; 94: 944-949.

31. Viner RM, Haines MM, Taylor SJC, Head J, Booy R, Stansfeld S. Body mass, weight control behaviour, weight perception and emotional well being in a multiethnic sample of early adolescents. Int J Obes 2006; 30: 1514-1521.

32. Wardle J, Williamson S, Johnson F, Edwards C. Depression in adolescent obesity: cultural moderators of the association between obesity and depressive symptoms. Int J Obes 2006; 30: 634-643. 
33. Smith E, Sweeting H, Wright C. "Do I care". Young adults recalled experiences of early adolescent overweight and obesity: a qualitative study. Int J Obes 2013; 37: 303-308.

34. Franklin J, Denyer G, Steibeck KS, Catrson ID, Hill AJ. Obesity and risk of self-esteem: A statewide survey of Australian children. Pediatrics 2006; 118: 2481-2487.

35. Wallander JL, Kerbawy S, Tooney S, et al. Is obesity associated with reduced health-related quality of life in Latino, black and white children in community? Int J Obes 2013; 37: 920-925.

36. Bluher M. Are there still healthy obese patients? Curr Opin Endocrinol Diabetes Obes 2012; 19: 341-346. 